\title{
Comparison of Low and High Current Density Proton Irradiation Effects on the Surface Morphology of Poly(tetrafluoroethylene)
}

\author{
G.U.L. NAGY ${ }^{a, b, *}$, Z. SzOBOSZlai ${ }^{a}$ AND I. RAJTA ${ }^{a}$ \\ ${ }^{a}$ Institute for Nuclear Research, Hungarian Academy of Sciences (MTA Atomki), \\ Bem tér 18/c, H-4026 Debrecen, Hungary \\ ${ }^{b}$ Institute of Physics, University of Debrecen, Bem tér 18/a, H-4026 Debrecen, Hungary
}

\begin{abstract}
A comparison is given about the effects of low and high current density proton irradiations on the surface topography of poly(tetrafluoroethylene). $1 \mathrm{MeV}$ proton beam was used for the experiments with 10 and $10^{8} \mathrm{pA} / \mathrm{mm}^{2}$ current densities. For the high current density irradiations, the beam was micro-focused, while for the low current density beam it was highly under-focused. The applied ion fluences were $0.1-1000 \mathrm{nC} / \mathrm{mm}{ }^{2}$ $\left(6.24 \times 10^{10}-6.24 \times 10^{14} \mathrm{ion} / \mathrm{cm}^{2}\right)$. Differential interference contrast microscopy, surface profilometry, and scanning electron microscopy were used to investigate the changes of the surface morphology. It is found that at low fluences the surface is etched similarly due to low and high current density irradiations, while at high fluences thermal processes differentiate the behaviour of the surface.
\end{abstract}

DOI: 10.12693/APhysPolA.136.250

PACS/topics: 78.70.--g, 79.20.Rf, 81.65.Cf

\section{Introduction}

The method of micromachining of materials using deep ion beam lithography was first presented in 1997 [1] and well established in the following years [2]. Since then various properties of different types of materials have been shown to be sensitive to $\mathrm{MeV}$ energy proton beam irradiation [3]. Among these materials, poly(tetrafluoroethylene) is one whose surface structure can be modified with $\mathrm{MeV}$ proton beams. Poly(tetrafluoroethylene) (PTFE, or as it is well known, Teflon) is a versatile material owing to its valuable technological properties, such as chemical inertness, high electrical resistivity, or low surface energy. It is known from the literature that the response of PTFE surface to $\mathrm{MeV}$ energy ion irradiation exhibits different behaviour depending on the irradiation circumstances. Thus, either indentations [4] or protrusions [5] can be fabricated using high energy proton beams. Surface modification of PTFE using other methods is also extensively studied (e.g. [6]).

However, high energy proton beam machining of materials spreads from the microworld to the nanoworld since the first appearance of true scanning nuclear nanoprobes [7]. Although strong efforts are made in order to increase the beam current in an even smaller beam spot [7-9] in contrast to the typical $10^{6}-10^{9} \mathrm{pA} / \mathrm{mm}^{2}$ current density of scanning nuclear microprobes [10-12], they usually achieve very small spot sizes with orders of magnitude lower current densities (e.g. [13]).

*corresponding author; e-mail: gyulanagy@atomki.mta.hu
At MTA Atomki, a new nanoprobe beamline attached to a Tandetron ${ }^{\top M}$ (High Voltage Engineering Europa B.V.) accelerator is recently being under construction. Since, at least in the present phase [14], it is not equipped with a high brightness ion source, the expected current density of the ultimate spot size is smaller than $10^{5} \mathrm{pA} / \mathrm{mm}^{2}$. Because of this, we started to investigate the morphological changes of PTFE surface due to low current density $\left(10-100,000 \mathrm{pA} / \mathrm{mm}^{2}\right)$ proton irradiation. The results are published elsewhere [15]. In the present paper, we give a comparison about the similarities and differences between the effects of low and high current density (focused) proton beam irradiation on PTFE.

\section{Experimental}

Smooth, pure, and large enough PTFE sample surfaces were needed for the irradiations. To satisfy these requirements, conventional grinding and polishing technique was chosen for the sample preparation. Figure 1 shows that the surface remained slightly wavy after the final polishing step, but if we take only a $250 \mu \mathrm{m}$ section, which is the width of the irradiated spots, is taken, the root mean square (RMS) roughness of the surface remains below $20 \mathrm{~nm}$, practically everywhere on the sample. It was acceptable to carry out the experiments since the proton beam induced changes turned out to be significantly larger.

The particle induced X-ray emission (PIXE) analysis was used to detect potential contaminants in the sample with the atomic numbers above aluminium (the PTFE itself consists of carbon and fluorine atoms; PIXE is not sensitive to them). Figure 2 shows the PIXE spectrum 


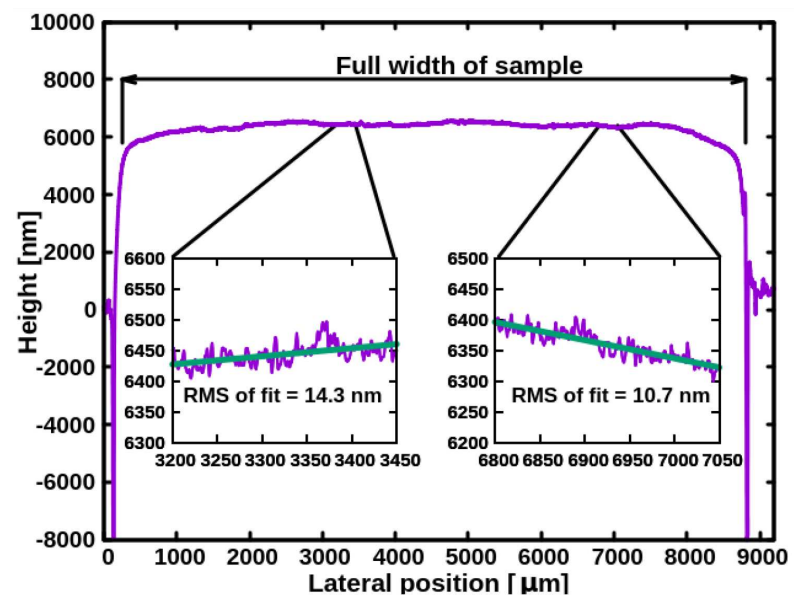

Fig. 1. Background roughness of a polished PTFE sample. The insets are arbitrarily chosen sections of $250 \mu \mathrm{m}$, which is the width of the irradiated spots.

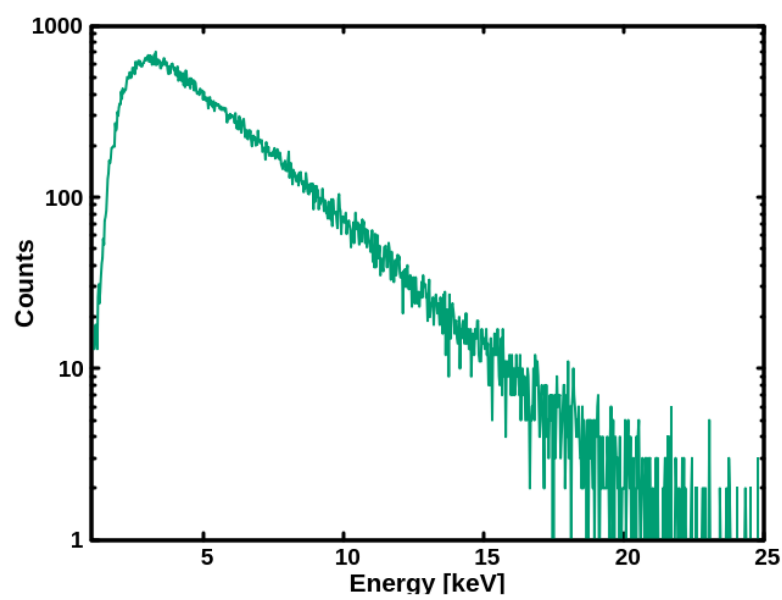

Fig. 2. Particle induced X-ray emission (PIXE) spectrum of a sample. No characteristic X-ray peaks are visible, i.e. the sample does not contain residuals from grinding and polishing.

in which no characteristic X-ray peaks can be seen, i.e. the sample does not contain residues from the grinding and polishing materials.

The $1 \mathrm{MeV}$ proton beam was used for the experiments, provided by the $5 \mathrm{MV}$ Van de Graaff accelerator of MTA Atomki. Two different types of irradiations were done, both in the vacuum chamber $\left(10^{-7}\right.$ mbar pressure range $)$ of the Oxford-triplet type scanning nuclear microprobe beamline.

For the high current density irradiations, $1000 \mathrm{pA}$ beam current was focused into a spot of less than $3 \times 3 \mu \mathrm{m}^{2}$. This is approximately $10^{8} \mathrm{pA} / \mathrm{mm}^{2}$ (note that the beam size is defined as the FWHM of the Gaussian-distributed beam spot). Then, the microbeam was scanned over a $250 \times 500 \mu \mathrm{m}^{2}$ area by two dipole magnets ( $X$ and $Y$ direction scan), to be able to detect the irradiated spot by the characterization techniques.
For the low current density irradiations, the scanning was turned off, and the beam was highly under-focused on a size-calibrated fluorescent screen: 5 pA beam intensity homogeneously distributed in a $250 \times 2000 \mu \mathrm{m}^{2}$ spot gave us $10 \mathrm{pA} / \mathrm{mm}^{2}$ current density. There is seven orders of magnitude difference in the current density, as well as in the power density of the beam $\left(10^{-5}\right.$ vs. $\left.100 \mathrm{~W} / \mathrm{mm}^{2}\right)$. Melting of the sample due to ion irradiation is a known and usually undesired phenomenon [16]. Thermally-assisted decomposition of PTFE due to helium ion irradiation was suspected by Torrisi et al. [17]. In our case a finite difference approximation of the 3-dimensional heat equation showed that in the case of the low current density irradiation, the temperature elevation of the sample is practically negligible. In contrast, in the case of high current density one, the temperature might exceed the melting point of PTFE $\left(327^{\circ} \mathrm{C}\right)$, especially in the so-called Bragg-peak where the beam loses most of its energy. Nonetheless, it seems that the scanning speed is a key factor, i.e. the time that the beam spends on a particular pixel during the scanning. From the simulation it turned out that in less than one millisecond the sample might melt (see Fig. 3).

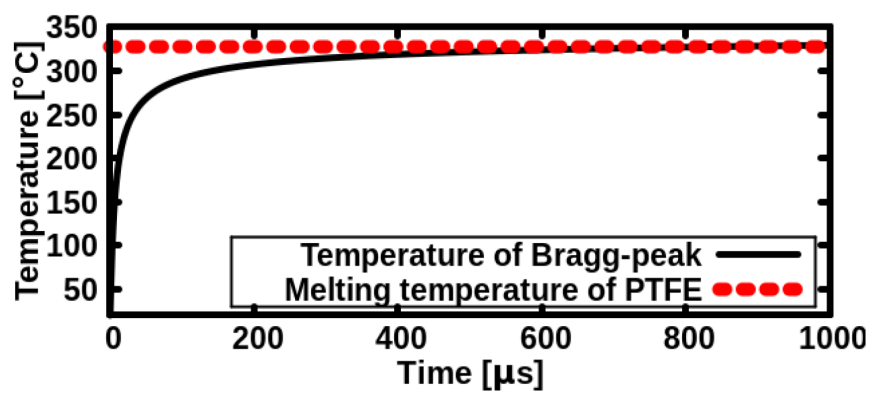

Fig. 3. Temperature evolution of the sample under focused proton beam irradiation. Finite difference simulation.

The applied ion fluence was between $0.1-500 \mathrm{nC} / \mathrm{mm}^{2}$ for the low current density irradiations, and $1-1000 \mathrm{nC} / \mathrm{mm}^{2}$ for the focused beam experiments, since the magnetic scanning system does not allow arbitrarily fast movement of the beam (i.e. arbitrarily low fluence is not feasible).

\section{Results and discussion}

The irradiations were first identified using differential interference contrast (DIC) microscopy. The structures are well seen even in the case of low fluences which suggests that the surface topography changed due to the irradiations (see Fig. 4). While applying high fluences at $500 \mathrm{nC} / \mathrm{mm}^{2}$ and above, the irradiated area darkened and some surface structure appeared in the case of both irradiations.

An Ambios XP-I stylus profiler was used for quantitative determination of the surface morphology change. 


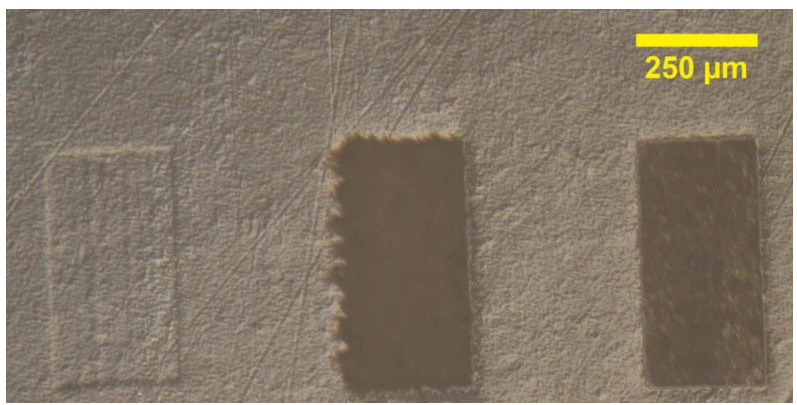

Fig. 4. Differential interference contrast microscopic image of irradiated spots. $10^{8} \mathrm{pA} / \mathrm{mm}^{2}$ fluences from left to right: 1,1000 , and $500 \mathrm{nC} / \mathrm{mm}^{2}$.

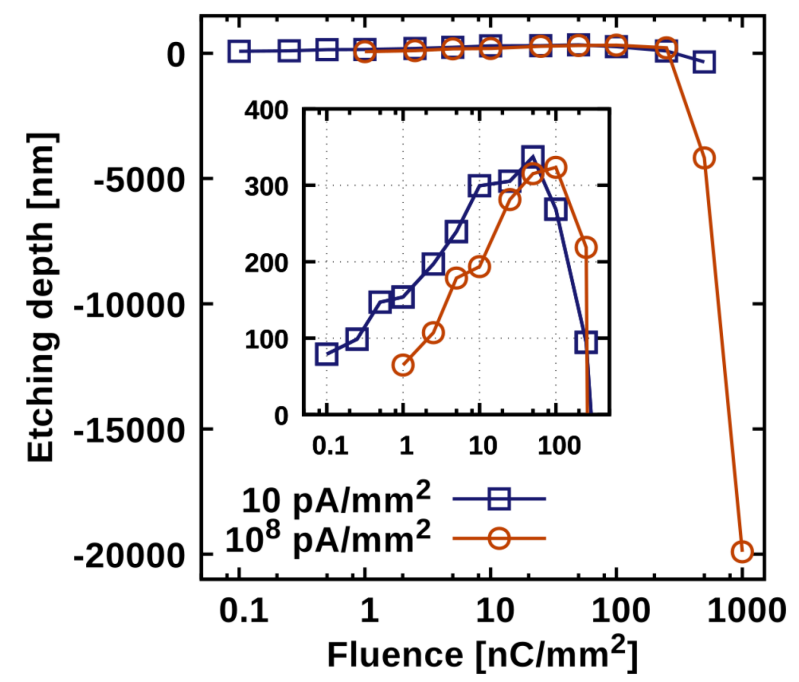

Fig. 5. Etching depth versus delivered fluence. First, regular etching happens, and the etching depth increases with the fluence. Then, it suddenly drops. At $500 \mathrm{nC} / \mathrm{mm}^{2}$ the values turn into negative, i.e. protrusions formed instead of indentations. The inset shows the positive values (i.e. indentations at low fluences).

The height of the proton beam irradiated spots was determined as a function of the delivered ion fluence as it can be seen in Fig. 5 .

The graph shows that at first the irradiated area is etched and the depth of the formed indentations starts to increase as the delivered fluence is increasing. These indentations are regular. Their size equals to that of the beam spot size (defocused beam) or scanned area size (focused, scanned beam), and their sidewalls are steep. Their surface is smooth, however, with the increasing ion fluence, the surface roughness tends to increase (see Ref. [15]). Between 50 and $100 \mathrm{nC} / \mathrm{mm}^{2}$, the etching depth reaches its maximum value. From here the depth starts to decrease and at $500 \mathrm{nC} / \mathrm{mm}^{2}$ it turns into negative. This indicates that at large fluences the surface becomes protruded instead of indented.

To find out what happens at large fluences, scanning electron microscope (SEM) was used to study the surface morphology of the irradiated samples. From the images it turned out that in the case of the focused beam, protrusions appeared (see Fig. 6) which is known from the literature, and explained by heating effects: the sample melted [18]. This observation is consistent with the results of the simulation shown in Fig. 3, since the pixel dwell time in this experiment exceeded $1 \mathrm{~ms}$ at exactly $500 \mathrm{nC} / \mathrm{mm}^{2}$ (it is noted that the overlapping pixels complicate the simple relation, time=fluence/current density, which would mean $1 \mathrm{~ms}$ irradiation time at $100 \mathrm{nC} / \mathrm{mm}^{2}$ ).

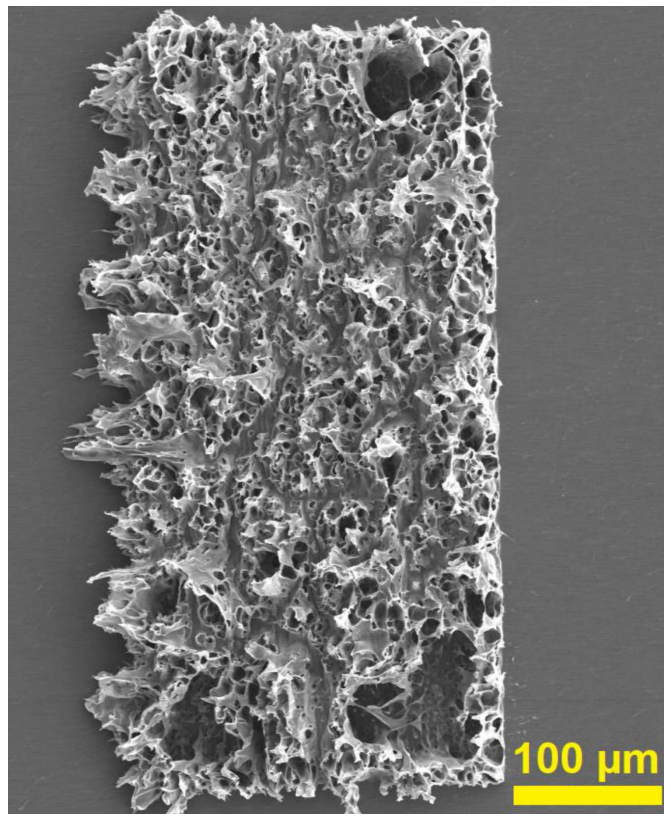

Fig. 6. Scanning electron microscope picture of a focused beam irradiation. Fluence: $1000 \mathrm{nC} / \mathrm{mm}^{2}$.

However, in the case of low current density beam, only some bubbling can be seen (see Ref. [15]) which is due to the internal gas generation caused by small CF molecules generated during ion irradiation [4].

\section{Conclusion}

It can be stated that although different thermal effects take place at low and high current density ion irradiations, in the case of low fluences the morphology of poly(tetrafluoroethylene) surface under proton beam irradiation behaves very similar for the two cases: the surface is etched by the beam. At high fluences differences between the focused and defocused irradiations are observed. In the former case, protrusions appeared due to sample melting, while in the case of the latter, only some inflation took place due to gas generation and bubble formation inside the bulk material.

\section{Acknowledgments}

Supported by the ÚNKP-17-3 New National Excellence Program of the Ministry of Human Capacities. 


\section{References}

[1] S.V. Springham, T. Osipowicz, J.L. Sanchez, L.H. Gan, F. Watt, Nucl. Instrum. Meth. Phys. Res. B 130, 155 (1997).

[2] J.A. van Kan, J.L. Sanchez, B. Xu, T. Osipowicz, F. Watt, Nucl. Instrum. Meth. Phys. Res. B $\mathbf{1 4 8}$ 1085 (1999).

[3] J.A. van Kan, P. Malar, Y.H. Wang, Appl. Surf. Sci. 310, 100 (2014).

[4] G.W. Grime, C.J. Sofield, I. Gomez-Morilla R. Gwilliam, M.D. Ynsa, O. Enguita, Nucl. Instrum. Methods Phys. Res. B 231, 378 (2005).

[5] A. Kitamura(Ogawa), T. Satoh, M. Koka, T. Kobayashi, T. Kamiya, Nucl. Instrum. Meth. Phys. Res. B 306, 288 (2013)

[6] A. Bartnik, H. Fiedorowicz, W. Skrzeczanowski, J. Czwartos, P. Wachulak, R. Jarocki, J. Kostecki, Acta Phys. Pol. A 133, 267 (2018).

[7] F. Watt, J.A.V. Kan, I. Rajta, A.A. Bettiol, T.F. Choo, M.B.H. Breese, T. Osipowicz, Nucl. Instrum. Meth. Phys. Res. B 210, 14 (2003).

[8] J.A.V. Kan, P. Malar, A.B. de Vera, Rev. Sci. Instrum. 83, 02B902 (2012).

[9] Y. Yao, J.A.V. Kan, Nucl. Instrum. Meth. Phys. Res. B 348, 203 (2015).

[10] I. Rajta, I. Borbély-Kiss, Gy. Mórik, L. Bartha, E. Koltay, Á.Z. Kiss, Nucl. Instrum. Meth. Phys. Res. B 109, 148 (1996).
[11] S. Lebed, Z. Stachura, M. Cholewa, G.J.F. Legge, J. Lekki, S. Maranda, A. Potempa, C. Sarnecki, Z. Szklarz, J. Styczen, B. Sulkio-Cleff, Nucl. Instrum. Meth. Phys. Res. B 181, 95 (2001).

[12] P. Vavpetič, M. Kelemen, B. Jenčič, P. Pelicon, Nucl. Instrum. Meth. Phys. Res. B 404, 69 (2017).

[13] P. Barberet, L. Daudin, N. Gordillo, S. Sorieul, M. Simon, H. Seznec, I. Idarraga, S. Incerti, A. Balana, P. Moretto, Nucl. Instrum. Meth. Phys. Res. B 269, 2163 (2011).

[14] I. Rajta, I. Vajda, G. Gyürky, L. Csedreki, Á.Z. Kiss, S. Biri, H.A.P.V. Oosterhout, N.C. Podaru, D.J.W Mous, Nucl. Instrum. Meth. Phys. Res. A 880, 125 (2018).

[15] G.U.L. Nagy, R. Kerékgyártó, A. Csík, L. Daróczi, I. Rajta, Nucl. Instr. Meth. Phys. Res. B 449, 71 (2019).

[16] S.Z. Szilasi, E. Baradács, I. Daruka, P. Raics, C. Cserháti, E. Dobos, I. Rajta, Nucl. Instrum. Meth. Phys. Res. B 231, 419 (2005).

[17] L. Torrisi, L. Calcagno, A.M. Foti, Nucl. Instrum. Meth. Phys. Res. B 32, 142 (1988)

[18] A. Kitamura, T. Kobayashi, T. Meguro, A. Suzuki, T. Terai, Surf. Coat. Technol. 203, 2406 (2009). 